\title{
Predictive Current Control with Instantaneous Reactive Power Minimization for a Four-Leg Indirect Matrix Converter
}

\author{
Cristian F. Garcia, Member, IEEE, Marco E. Rivera, Member, IEEE, José R. Rodríguez, Fellow Member, \\ IEEE, Pat W. Wheeler, Senior Member, IEEE, Rubén S. Peña, Member, IEEE
}

\begin{abstract}
This paper presents the experimental validation of a predictive current control strategy with minimization of the instantaneous reactive input power for a FourLeg Indirect Matrix Converter (4Leg-IMC). The topology includes an input matrix converter stage, which provides the $d c$ voltage for a four-leg voltage source converter (VSC) output stage. The VSC's fourth leg provides a path for the zero sequence load current. The control technique is based on a finite control set model predictive control (FCS-MPC) strategy, whereby the switching states for the input and output converters are selected by evaluating a predictive cost function. This results in a simpler approach than that seen in other well-known modulation methods, such as threedimensional space vector modulation (3D-SVM). Positive $d c$ voltage, (a requirement for the safe operation of the IMC) and minimization of the instantaneous input reactive power are obtained, while maintaining good tracking of the load reference currents. Furthermore, soft switching is achieved by synchronizing the state changes in the input stage with the application of zero voltage space vectors in the inverter stage. The control strategy is experimentally verified using a laboratory prototype.
\end{abstract}

Index Terms-Matrix Converters, Predictive Control, Current Control, AC-AC Conversion.

Manuscript received November 3, 2015; revised March 17, 2016 and May 28, 2016; accepted June 23, 2016. This work was supported in part by Centro Basal FB0008 Advanced Center for Electrical and Electronics Engineering (AC3E), in part by the Fondecyt 1160690 , in part by the Fondecyt 1150829 and in part by CONICYT/FONDAP/15110019.

C. Garcia is with the Department of Electronics Engineering, Universidad Técnica Federico Santa María, Av. España 1680, Valparaíso, Chile (e-mail: cristian.garciap@alumnos.utfsm.cl).

M. Rivera is with the Department of Industrial Technologies, Universidad de Talca, Talca 3460000, Chile (e-mail: marcoriv@utalca.cl).

$\mathrm{J}$. Rodríguez is with the Faculty of Engineering, Universidad Andres Bello, Santiago 8370146, Chile (e-mail: jose.rodriguez@unab.cl).

P. Wheeler is with the Department of Electrical and Electronic Engineering, The University of Nottingham, Nottingham, NG7 2RD, U.K. (e-mail: pat.wheleer@nottingham.ac.uk).

R. Peña is with the Department of Electrical Engineering, University of Concepción, Concepción 160-C, Chile (e-mail: rupena@udec.cl).

\section{NOMENCLATURE}

$\mathbf{i}_{\mathrm{s}} \quad$ Source current

$\mathbf{v}_{\mathbf{s}} \quad$ Source voltage

$\mathbf{i}_{\mathbf{i}} \quad$ Input current

$\mathbf{v}_{\mathbf{i}} \quad$ Input voltage

$v_{d c} \quad d c$-link voltage

$\mathbf{i}_{\mathbf{o}} \quad$ Load current

$\mathbf{v}_{\mathbf{o}} \quad$ Load voltage

$\mathbf{i}_{\mathbf{O}}^{*}$

$C_{f}$

$L_{f}$

$R_{f}$

$R_{L}$

$L_{L}$$$
\text { Output current }
$$

Filter capacitor

Filter inductor

Filter resistor

Load resistance $i_{d c} \quad d c$-link current

$$
\begin{aligned}
& {\left[\begin{array}{lll}
i_{s A} & i_{s B} & i_{s C}
\end{array}\right]^{T}} \\
& {\left[\begin{array}{lll}
v_{s A} & v_{s B} & v_{s C}
\end{array}\right]^{T}} \\
& {\left[\begin{array}{lll}
i_{A} & i_{B} & i_{C}
\end{array}\right]^{T}} \\
& {\left[\begin{array}{lll}
v_{A} & v_{B} & v_{C}
\end{array}\right]^{T}}
\end{aligned}
$$

Load inductance

\section{INTRODUCTION}

$\mathbf{I}$ $\mathrm{N}$ recent years there has been an increased interest in applications of direct power converters, such as the direct matrix converter (DMC), the indirect matrix converter (IMC) and other derived topologies. These topologies offer a direct $a c-a c$ conversion and due to the absence of $d c$-link capacitors they are more compact, robust and reliable. They simultaneously achieve sinusoidal input and output waveforms as well as bidirectional power flow [1]-[5]. Compared to a conventional back-to-back inverter, which requires bulky storage elements, the space saved by a direct power converter has been estimated as a factor of three. This characteristic enables this kind of power converters to be used in portable generation systems, for instance in variable speed diesel generation, variable speed wind-diesel topologies, distributed generation applications, emergency vehicles, military and aerospace applications, external elevators for building construction and skin pass mills [3], [5], [6].

When energy is to be supplied to a three-phase load it is necessary to take into account any unbalanced nature of the load and the need for a path for the zero sequence current. This path could be provided by using a four-leg VSC on the load side. The fourth leg would then provide the needed neutral connection for the load. There are several topologies that can handle the zero sequence voltage and the current caused by an unbalanced source or load in three-phase, four-wire systems [7], [8]. A direct power converter can also be used to 


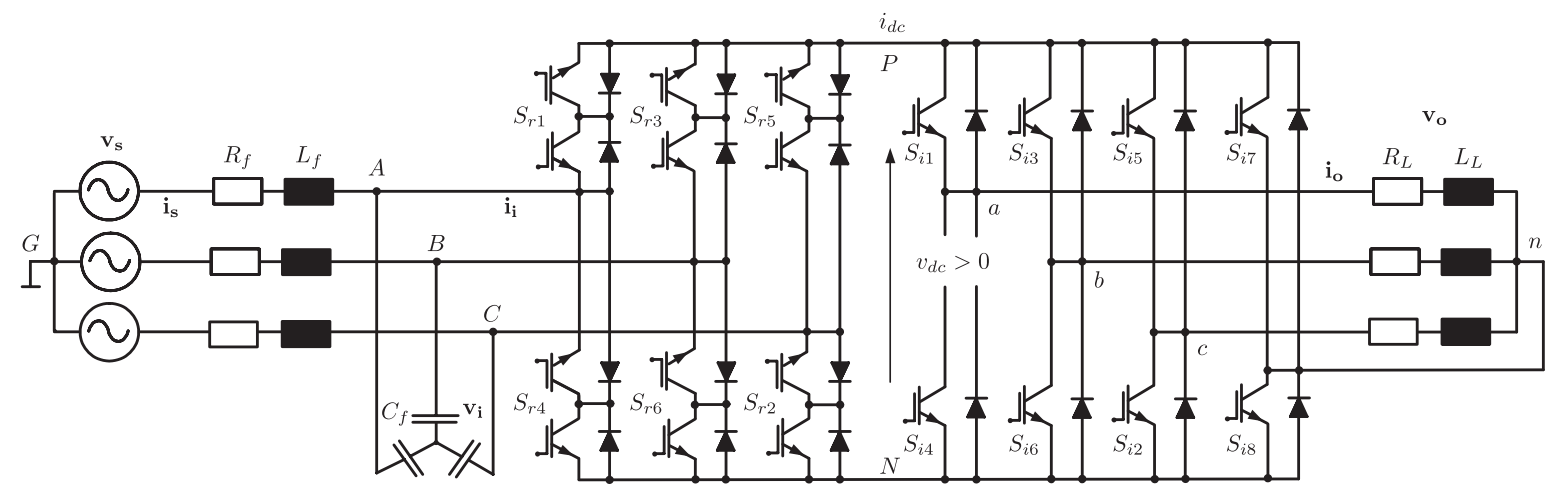

Fig. 1. Circuit topology of a four-leg indirect matrix converter.

supply energy to an unbalanced three-phase load using a 4LegIMC [9], [10]. This type of converter is normally modulated using carrier-based pulse-width modulation (PWM) or threedimensional space vector modulation (3D-SVM) techniques [11], [12]. Compared to the carrier-based PWM technique, the 3D-SVM offers many advantages such as good $d c$-link utilization and minimum output distortion, but it has a higher computational requirement and is therefore not intuitive for implementation [13].

Model predictive control (MPC) is an attractive alternative to the aforementioned classical methods due to its fast dynamic response and simple concept as well as the possibility to include other constraints in the design. The continuous control set MPC [14] and non-linear MPC [15] that were previously analyzed for four-leg converters use intricate modeling as well as a modulation stage and thus they are not intuitive. Recently, predictive control has been applied to control the load of a 4Leg-IMC [16], [17]. Only simulation results have been presented, but in [18] the basic strategy, which includes only the load current control, has been experimentally validated. A good tracking of the output current was achieved but with distorted input currents. This paper presents a control strategy aiming to track the output current and minimize the input instantaneous reactive power of a 4Leg-IMC. A FCS-MPC is proposed for the regulation of the output current. MPC utilizes an optimization function that considers all possible combinations of the switching states. However, due to the discrete nature of power converters, and since the 4LegIMC has a finite number of switching states (sixteen for the inverter side and nine for the rectifier side), the predictions and optimizations are greatly simplified; they can thus be digitally implemented in current microprocessors. Unlike control strategies based on carrier-based PWM or 3D-SVM, this scheme does not require internal current control loops and modulators, which greatly reduces its complexity. For the implementation of the control strategy, soft switching operation of the input stage is considered. This issue is well known for standard PWM SVM approaches, but it is not trial when predictive current control is used. Therefore, the soft switching capability of the IMC is maintained by setting a null vector in the output stage when a commutation is needed in the input stage. This soft switching does not degrade the performance of the converter. This technique has been successfully applied to a wide range of power converters [19]-[22]. Transient and steady state experimental results are presented for balance and unbalanced load. The large number of computations, the safe operation of the converter and the effective control of both the input and output side waveforms have been validated and demonstrated in this work using a simple predictive control strategy. It is important highlight that classical modulation and control techniques for matrix converters, particularly fourleg matrix converters, are not easy tasks because they require 3D transformations [23], [24]. By using predictive control an intuitive control strategy can be deployed and this strategy can be considered as an effective alternative for the control of this kind of converter.

\section{Proposed PREDictive CuRRENT CONTROL STRATEGY FOR THE 4LEG-IMC}

The complete topology of the 4Leg-IMC is shown in Fig. 1. The authors have reported the mathematics model of the system in [16], [17], [25], [26], as a function of the input and output variables as well as the valid commutation states of the converter. The main constraints are to always ensure a positive $d c$-link voltage and to avoid short circuits at the input and open lines at the output side of the converter.

\section{A. Control scheme}

The proposed control method, that is experimentally validated in this paper, is shown in Fig. 2. The method seeks to apply the switching state that generates the output current $\mathbf{i}_{\mathrm{o}}$ closest to the reference current given by $\mathbf{i}_{\mathbf{o}}{ }^{*}$, generates a positive voltage in the $d c$-link and minimize the instantaneous input reactive power. The control objectives are developed by following three steps:

1) The reference output current is defined as $\mathbf{i}_{\mathbf{o}}{ }^{*}$, the reference of the instantaneous reactive power is zero, $q_{s}^{*}=0$, and the condition of $v_{d c}>0$ is set. The source voltage, $\mathbf{v}_{\mathbf{s}}(k)$, the source current, $\mathbf{i}_{\mathbf{s}}(k)$, the converter input voltage, $\mathbf{v}_{\mathbf{i}}(k)$, and the output current, $\mathbf{i}_{\mathbf{o}}(k)$, are all measured.

2) The measurements and model of the system are used to estimate the load voltage, $\mathbf{v}_{\mathbf{o}}(k+1)$, and predict the value of the source current, $\mathbf{i}_{\mathbf{s}}(k+1)$, the $d c$-link voltage, 


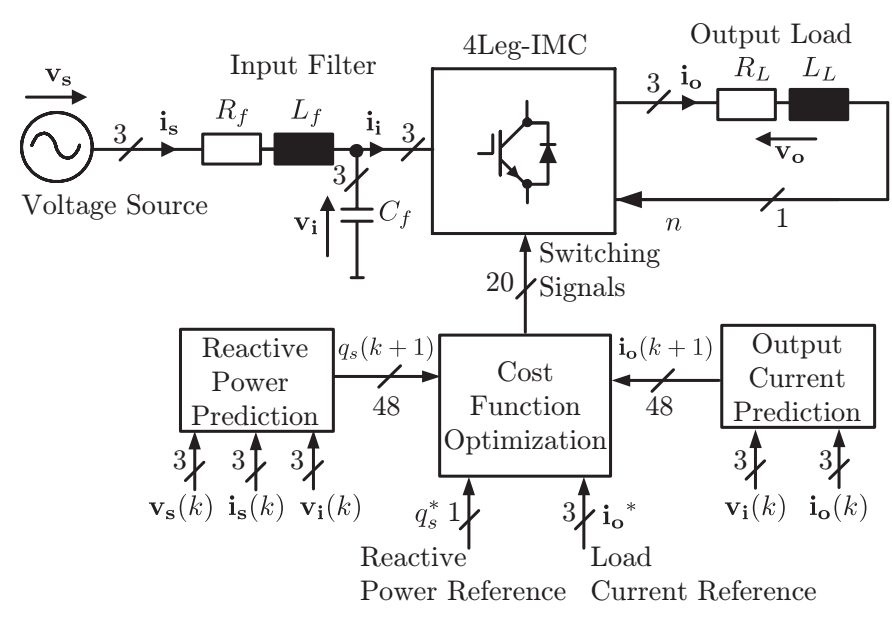

Fig. 2. Predictive current control scheme with minimization of instantaneous reactive input power.

$v_{d c}(k+1)$, and the load current, $\mathbf{i}_{\mathbf{o}}(k+1)$, for the next sampling period for each of the valid switching states.

3) In the last step the predicted values are evaluated in the cost function, $g$. The switching state that minimizes the cost function (produces the least error) is selected and applied during the next sample period.

\section{B. Prediction model}

The discrete nature of power converters and control platforms gives rise to the requirement that the system equations be formulated in discrete time. The prediction variables for the input side are given as:

$$
\left[\begin{array}{c}
\mathbf{v}_{\mathbf{i}}(k+1) \\
\mathbf{i}_{\mathbf{s}}(k+1)
\end{array}\right]=\phi\left[\begin{array}{c}
\mathbf{v}_{\mathbf{i}}(k) \\
\mathbf{i}_{\mathbf{s}}(k)
\end{array}\right]+\gamma\left[\begin{array}{c}
\mathbf{v}_{\mathbf{s}}(k) \\
\mathbf{i}_{\mathbf{i}}(k)
\end{array}\right],
$$

where, $\phi \cong e^{\mathbf{A} T_{s}}$ and $\gamma \cong \mathbf{A}^{-1}\left(\phi-\mathbf{I}_{2 x 2}\right) \mathbf{B}$ with,

$$
\mathbf{A}=\left[\begin{array}{cc}
0 & 1 / C_{f} \\
-1 / L_{f} & -R_{f} / L_{f}
\end{array}\right], \mathbf{B}=\left[\begin{array}{cc}
0 & -1 / C_{f} \\
1 / L_{f} & 0
\end{array}\right]
$$

The voltage $v_{d c}$ is defined by the input voltage at 4Leg-IMC $\mathbf{v}_{\mathbf{i}}$ and the matrix of the rectifier states $T_{r}$ [16]. Therefore, the $d c$-link voltage in the next sample time $k+1$ is given by:

$$
v_{d c}(k+1)=T_{r}(k+1) \mathbf{v}_{\mathbf{i}}(k) .
$$

The discrete expression of the output current $\mathbf{i}_{\mathbf{o}}$ is obtained by using the Euler approximation:

$$
\mathbf{i}_{\mathbf{o}}(k+1)=\frac{T_{s}}{L_{L}} \mathbf{v}_{\mathbf{o}}(k)+\left(1-\frac{R_{L}}{L_{L}} T_{s}\right) \mathbf{i}_{\mathbf{o}}(k),
$$

where $T_{s}$ is the sample time, $\mathbf{i}_{\mathbf{o}}$ is the measure of the output current at instant $k$, and $\mathbf{v}_{\mathbf{o}}$ is the estimation of the output voltage at time instant $k$, which is obtained as a function of the valid switching states of the converter.

The input filter is intended to eliminate/reduce high order harmonics contained in converter input current due to intrinsic switching nature of the converter. A low pass damped LC filter is designed in order to have a proper operation of the converter under the predictive control strategy presented in the paper, the high order harmonics are distributed below the switching frequency [27]-[29]. After a thorough simulation work and frequency analysis of the converter input current, considering balanced current and load references, the input filter parameters were finally selected in order to have a proper performance over the entire operating range of the converter. The filter transfer function is given as:

$$
I_{s}(s)=H_{v}(s) \cdot V_{s}(s)+H_{i}(s) \cdot I_{i}(s),
$$

where,

$$
\begin{aligned}
& H_{v}(s)=\frac{s C_{f}}{s^{2} L_{f} C_{f}+s R_{f} C_{f}+1}, \\
& H_{i}(s)=\frac{1}{s^{2} L_{f} C_{f}+s R_{f} C_{f}+1} .
\end{aligned}
$$

The frequency $\omega_{n}$ and the damping factor $\zeta$ are given by:

$$
\begin{gathered}
\omega_{n}=\frac{1}{\sqrt{L_{f} C_{f}}}, \\
\zeta=\frac{1}{2} R_{f} \sqrt{\frac{L_{f}}{C_{f}}} .
\end{gathered}
$$

A discretized version of the filter is used in the implementation of the control strategy for the prediction of the input current. As seen from the experimental results the used filter structure provides adequate performance, with no stability problems encountered, without the need to include some other damping effect to the filter such as those reported in [28], [30]-[32], where a virtual damping resistor is considered in parallel to the filter capacitor.

\section{Cost function definition}

The control objectives of the proposed strategy are included in the cost function, $g$. Here, the error between the reference and the prediction for each of the control objectives is evaluated. The load current, $\mathbf{i}_{\mathbf{o}}$, must be controlled; to this end the quadratic error between the reference and the prediction for phases $(a-b-c)$ are calculated, and thus the function that determines the error of the load current is obtained:

$$
\triangle i_{o}(k+1)=\left(i_{a}^{*}-i_{a}\right)^{2}+\left(i_{b}^{*}-i_{b}\right)^{2}+\left(i_{c}^{*}-i_{c}\right)^{2},
$$

where $i_{a}, i_{b}$ and $i_{c}$ represent the predicted current of the load at coordinates $a b c$ for sample time $k+1 ; i_{a}^{*}, i_{b}^{*}$ and $i_{c}^{*}$ are their respective references. Further, the instantaneous reactive power, $q_{s}$, must be minimized. For this, the reference $q_{s}^{*}=0$ is used. The function that determines the minimization of the instantaneous reactive power is:

$$
\triangle q_{s}(k+1)=\left(v_{s \alpha} i_{s \beta}-v_{s \beta} i_{s \alpha}\right)^{2} .
$$

The final control objective is to ensure a positive voltage in the $d c$-link. This objective can be incorporated into the cost function $g$, but this increases the processing time. Its incorporation in the cost function causes an increase in the required calculations. Therefore, it is preferable to do the calculations prior to the optimization. There are six possible values for the voltage in the $d c$-link of which only three are 
TABLE I

SUMMARY OF STEADY-STATE ANALYSIS FOR EXPERIMENTAL RESULTS.

\begin{tabular}{|c|c|c|c|c|c|c|}
\hline Case & Phase & Frequency [Hz] & Amplitude [A] & {$[\%]$ THD $\mathbf{i}_{\mathbf{o}}$} & {$[\%] \bar{e}_{i}$} & {$[\%]$ THD $\mathrm{i}_{\mathrm{s}}$} \\
\hline \multirow{4}{*}{ Case-1 } & $\bar{a}$ & \multirow{4}{*}{60} & 6 & 4.9210 & 3.3496 & 4.5142 \\
\hline & $b$ & & 6 & 4.9087 & 3.0140 & 4.5125 \\
\hline & $c$ & & 6 & 4.8255 & 2.9828 & 4.6206 \\
\hline & avg & & & 4.8850 & 3.1155 & 4.5491 \\
\hline \multirow{4}{*}{ Case-2 } & $a$ & \multirow{4}{*}{60} & 6 & 4.8516 & 2.8578 & 4.4600 \\
\hline & $b$ & & 6 & 4.7305 & 2.5766 & 4.4807 \\
\hline & $c$ & & 6 & 4.5109 & 2.5407 & 4.5411 \\
\hline & avg & & & 4.6976 & 2.6584 & 4.4939 \\
\hline \multirow{4}{*}{ Case-3 } & $a$ & \multirow{4}{*}{60} & 4 & 8.4806 & 2.3691 & 4.5992 \\
\hline & $b$ & & 6 & 7.4932 & 2.7599 & 4.4532 \\
\hline & $c$ & & 8 & 4.4598 & 2.9998 & 4.3296 \\
\hline & avg & & & 6.8112 & 2.7096 & 4.4606 \\
\hline
\end{tabular}

positive in any given sample time. Three switching states can thus be eliminated for each sample time and the processing time is reduced. The cost function can therefore be expressed as:

$$
g(k+1)=\triangle i_{o}(k+1)+\lambda_{q} \triangle q_{s}(k+1),
$$

in eq. (12) $\lambda_{q}$ is the weighted factor for the minimization of the instantaneous reactive power. The selection of the weighting factor $\lambda_{q}$ is obtained by calculating the THD of the input and output currents; the factor which generates the least THD for both currents is selected. Several control objectives, variables, and constraints can be included in the cost function, allowing a simultaneous control of all of them. However, when these control objectives are of a different nature, their combination in the cost function is not easy to implement and requires some weighting factors in order to prioritize between one control objective and another. This is still an open issue for research because there are no analytical or numerical procedures to adjust these parameters, they are usually determined using empirical methods. [33] and [34] introduce different types of cost functions as well as procedures to select and adjust the optimal weighting factors depending on the application and type of cost function. An alternative implementation that does not requires weighting factors has been presented recently [35]. To determine the optimum value of the weighting factors for this application the THD criteria has been used. A comparative table with THD of output and input currents for different weighting factor values, similar to the Table I, can be created to choose the best values. The weighting factor values that minimizes the THD of both the output and input currents is then selected for use in the cost function.

\section{EXPERIMENTAL RESULTS}

\section{A. Description of the experimental setup}

In order to validate and demonstrate the feasibility of the proposed current control method with minimization of the instantaneous reactive input power, an experimental prototype designed by University of Nottingham has been used with the parameters detailed in Table II.

The converter was built with Semikron SKM75GB123D dual IGBT modules for the rectifier side and a Semitop SK35GD126ET module for the inverter side. The control algorithm has been implemented using a host PC running
MATLAB-Simulink $2006 a$ software with Real-Time Interface (RTI). The dSPACE DS1103 controller is used to handle the control processes such as load current prediction, load voltage estimation, and cost function minimization. The load currents are measured by LEM LAH 25-NP sensors. Feedback from the sensors is sent to the controller through the DS1103 I/O connector. The switching state to be applied in the converter is sent from the dSPACE to a FPGA Spartan 6, which performs the zero $d c$-link commutation strategy in order to operate the converter safely. The converter requires a commutation sequence that allows a safe change of the rectifier switching state. This problem can be addressed by synchronizing the state changes in the rectifier with the application of a zero voltage space vector in the inverter stage. Under this condition no current circulates through the $d c$-link and the rectifier state can be changed without the help of auxiliary commutation circuits [36].

\section{B. Delay compensation}

A large number of calculations are required in the predictive algorithm and this causes a considerable time delay in the actuation. This delay can deteriorate the performance of the system if it is not considered in the design of the controller. A solution to compensate for this delay is to calculate the cost function at the end of the next sampling period, $g(k+2)$. Thus, the selected switching state can be applied at instant $k+1$, and therefore one sampling period is available for calculations. To accomplish this, the control scheme is experimentally implemented as follows:

1) Measurement of the load currents.

TABLE II

EXPERIMENTAL PARAMETERS USED IN THE IMPLEMENTATION

\begin{tabular}{l|l|l} 
Variables & Description & Value \\
\hline \hline$T_{s}$ & Sampling time & $30[\mu \mathrm{s}]$ \\
$V_{s}$ & Supply phase voltage & $141\left[\mathrm{~V}_{p h}\right]$ \\
$f_{s}$ & Supply frequency & $50[\mathrm{~Hz}]$ \\
$L_{f}$ & Input filter inductance & $15[\mathrm{mH}]$ \\
$C_{f}$ & Input filter capacitance & $51[\mu \mathrm{F}]$ \\
$R_{f}$ & Input filter resistance & $1[\Omega]$ \\
$R_{L}$ & Load resistance & $10[\Omega]$ \\
$L_{L}$ & Load inductance & $15[\mathrm{mH}]$ \\
$\lambda_{q}$ & Weight factor & 0.0009 \\
\hline \hline
\end{tabular}




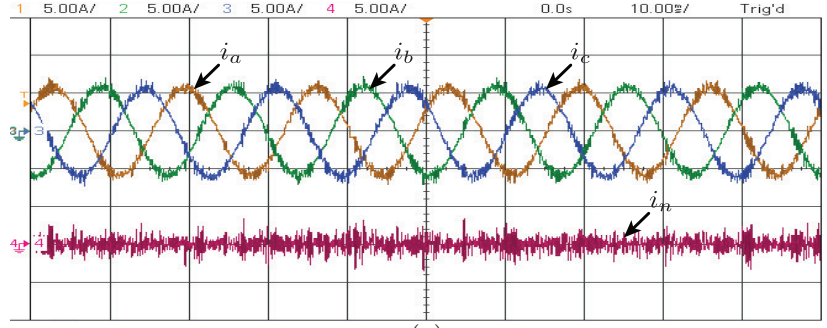

(a)

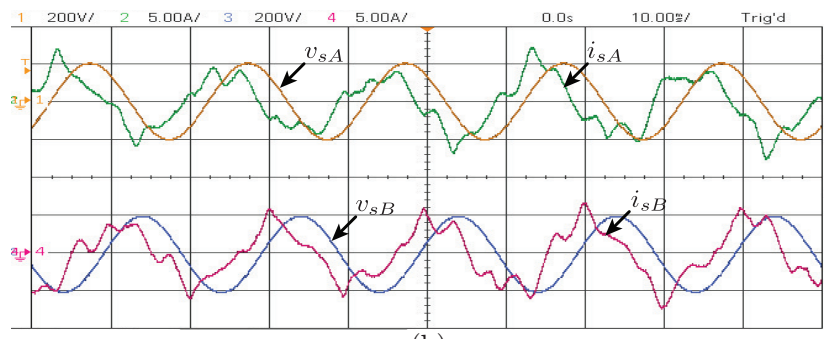

(b)

Fig. 3. Results without minimization $q_{s}$, balanced reference and balance load; (a) $f=60[\mathrm{~Hz}]$ top: output current $\mathbf{i}_{\mathbf{o}}$, bottom: neutral current $i_{n}$. (b) top: source voltage $v_{s A}$ and current $i_{s A}$, bottom: source voltage $v_{s B}$ and current $i_{s B}$.

2) Apply the switching state (calculated in the previous interval).

3) Estimate the current values at time $k+1$, considering the applied switching state.

4) Predict the load current for the next sampling instant $k+2$ for all possible switching states.

5) Evaluate the cost function for each prediction.

6) Select the switching state that minimizes the cost function.

\section{Experiment Results}

In order to validate the proposed control strategy, different tests have been experimentally implemented. In all the tests the following load current references are considered:

$$
\begin{aligned}
& i_{a}^{*}(k+1)=I_{a} \sin (\theta), \\
& i_{b}^{*}(k+1)=I_{b} \sin (\theta-2 \pi / 3), \\
& i_{c}^{*}(k+1)=I_{c} \sin (\theta+2 \pi / 3),
\end{aligned}
$$

where $I_{a}, I_{b}$ and $I_{c}$ correspond to the amplitudes of phase $a, b$ and $c$ and $\theta$ the reference angle, respectively. The performance of the proposed control strategy is shown in Fig. 3 and Fig. 4. Both experiments have a reference output current $\mathbf{i}_{\mathrm{o}}{ }^{*}$, balanced $I_{a}=I_{b}=I_{c}=6[\mathrm{~A}]$, and an output frequency of $f=60[\mathrm{~Hz}]$. The tracking of the references is good in both cases; neither stationary error nor high ripple are observed. In Fig. 3 the instantaneous reactive input power is not controlled, therefore the shape of the input current waveform $\mathbf{i}_{\mathbf{s}}$ is significantly distorted and out of phase with its voltage, as can be seen in Fig. 3(b). This is also affected by the resonance of the input filter produced by the commutations of the switches. In Fig. 4 the instantaneous reactive input power is controlled, and for that reason the shape of the input current waveform $i_{s}$ is sinusoidal and in phase with its respective voltage, as it can be seen in Fig. 4(b). Fig. 4(c) shows the $d c$-link voltage in the

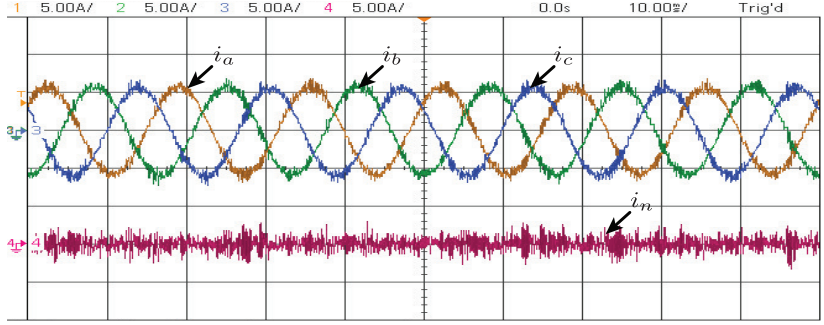

(a)

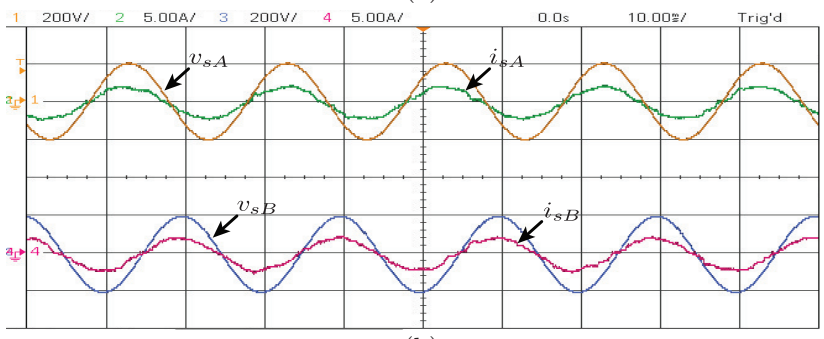

(b)

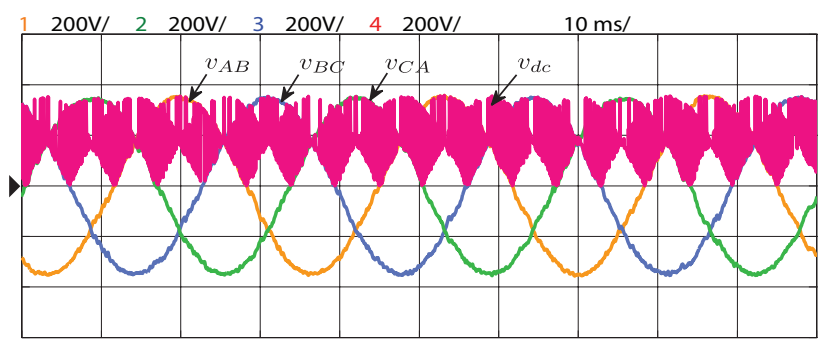

(c)

Fig. 4. Results with minimization $q_{s}$, balanced reference and balance load; (a) $f=60[\mathrm{~Hz}]$ top: output current $\mathbf{i}_{\mathbf{o}}$, bottom: neutral current $i_{n}$. (b) top: source voltage $v_{s A}$ and current $i_{s A}$, bottom: source voltage $v_{s B}$ and current $i_{s B}$. (c) The $d c$-link voltage and line-to-line voltage measured at the capacitor filter.

matrix converter where it is observed that it is synthesized to the two maximum positive line-to-line input voltages.

In Fig. 5 the operation of the 4Leg-IMC with an unbalanced reference, balanced load impedance, is shown with $I_{a}=4[\mathrm{~A}]$, $I_{b}=6[\mathrm{~A}], I_{c}=8[\mathrm{~A}]$ and a frequency of $f=60[\mathrm{~Hz}]$. The tracking of the output current references is good and neither a notable stationary error nor a high ripple are observed. This is the typical application for three-phase, fourwire systems where the load demand varies during each phase. The controller handles each phase current independently and thus the load currents track to their references with low steady-state error. This proves that the predictive strategy can control each current independently. The neutral-current, which is the sum of the three-phase currents, flows through the fourth leg and presents a sinusoidal waveform because the unbalanced references are given with the same reference frequency. The control of the instantaneous reactive power minimization is achieved, the input currents and voltages are in phase. The shape of the input current is not sinusoidal due to the requirement for unbalanced output currents. In a matrix converter, where the input and output are direct connection, unbalances in the output currents implicate unbalance in the input currents.

Fig. 6 shows the effect of the instantaneous reactive input power control. During the first 50 [ms] the instantaneous 


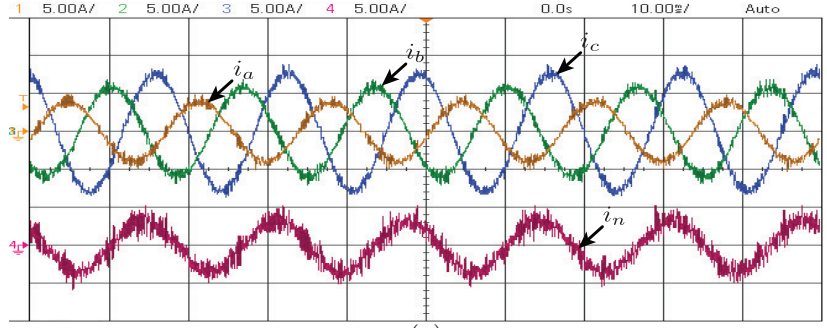

(a)

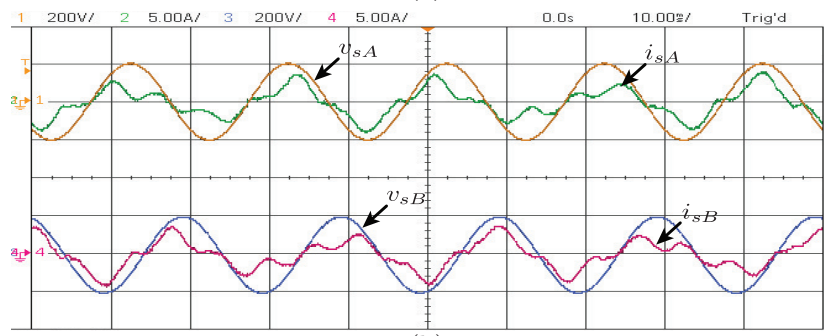

(b)

Fig. 5. Results with minimization $q_{s}$, unbalanced reference and balance load; (a) $f=60[\mathrm{~Hz}]$ top: output current $\mathbf{i}_{\mathbf{o}}$, bottom: neutral current $i_{n}$. (b) top: source voltage $v_{s A}$ and current $i_{s A}$, bottom: source voltage $v_{s B}$ and current $i_{s B}$.

reactive input power is not controlled which means that the weighting factor $\lambda_{q}=0$; an average value of 750 [VAR] is obtained. After $\mathrm{t}=50[\mathrm{~ms}]$, the instantaneous reactive input power is controlled considering $\lambda_{q}=0.0009$, obtaining almost zero instantaneous reactive input power. The effect of including or excluding the term that minimizes the instantaneous reactive power is also reflected in the source current $\mathbf{i}_{\mathbf{s}}$, as depicted in Fig. 6(b). A source current that is almost sinusoidal and in phase with its respective source voltage is obtained when $\lambda_{q}=$ 0.0009 . With these results it has been demonstrated that it is possible to control both the input and output sides of a 4LegIMC with predictive control and that this is an effective and easily implemented alternative to classical control strategies.

\section{Performance Assessment}

For each case presented in the previous section, Table I shows the analysis for each phase considering the average error, $\% e_{i x}$, and the THD (Total Harmonics Distortion) defined as:

$$
\% e_{i x}=\frac{1}{m} \sum_{k=0}^{m}\left|i_{x}^{*}(k)-i_{x}(k)\right| \cdot 100 \%,
$$

where $x=a, b, c$, and $m$ total number of data.

$$
\% \text { THD of phase }-x=\frac{\sqrt{i_{2, x}^{2}+i_{3, x}^{2}+\ldots+i_{n, x}^{2}}}{i_{1, x}} \cdot 100 \% \text {, }
$$

where $x=a, b, c$, and $i_{n, x}$ and $i_{1, x}$ are $n^{t h}$ harmonic and the fundamental component of the phase $x$ of the load current, respectively.

As observed, most of the $\% e_{i x}$ and THD for each case is less than $3 \%$ and $5 \%$, respectively, despite the sampling time considered $\left(T_{s}=30 \mu \mathrm{s}\right)$. When the term that minimizes the instantaneous reactive input power is included in the cost function both input and load currents are improved, which is

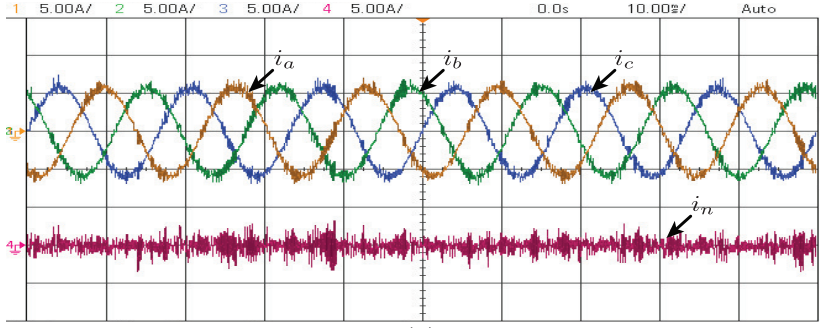

(a)

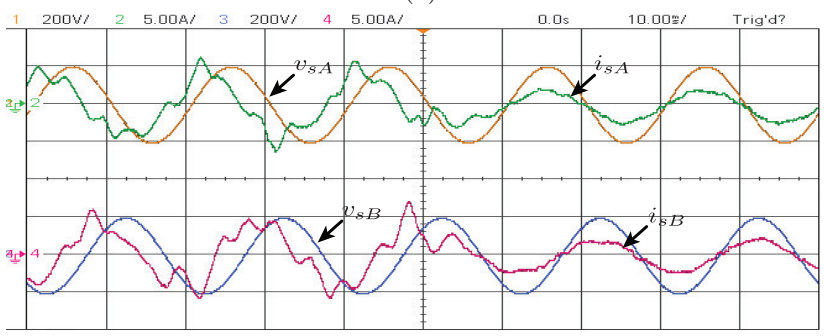

(b)

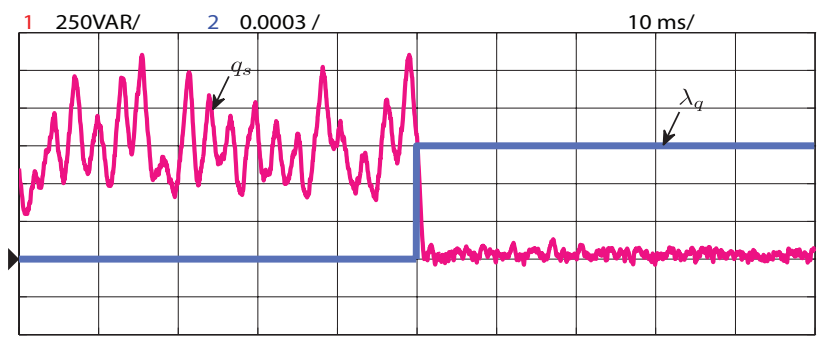

(c)

Fig. 6. Dynamics response with and without minimization $q_{s}$, balanced reference and balance load; (a) $f=60[\mathrm{~Hz}]$ top: output current $\mathbf{i}_{\mathbf{o}}$, bottom: neutral current $i_{n}$. (b) top: source voltage $v_{s A}$ and current $i_{s A}$, bottom: source voltage $v_{s B}$ and current $i_{s B}$. (c) Instantaneous reactive power $q_{s}$ and weight factor $\lambda_{q}$.

reflected in the reduction of the $\% e_{i x}$ and THD. The higher value of $\% e_{i x}$ and THD is given in the load current when their references are unbalanced, but, at the same time, the input currents maintain a low $\% e_{i x}$ and THD. This effect could be given by the selection of the weighting factor that is not the optimal in a given case. As mentioned before, the selection of this value is empirical and the optimization of this value is beyond the scope of this paper.

\section{CONCLUSION}

In this paper a predictive current control strategy with instantaneous reactive power minimization for a four-leg indirect matrix converter has been experimentally validated, obtaining sinusoidal input and output currents with low average error and current THD at different operation points. Experimental results have demonstrated that predictive control is very effective because it considers, in a very convenient way, the discrete nature of the converter switching states and the discrete nature of the microprocessor used to perform the control strategy. By approaching the control task from this different perspective a very attractive alternative control for power electronics has been demonstrated. 


\section{REFERENCES}

[1] X. Li, M. Su, Y. Sun, H. Dan, and W. Xiong, "Modulation strategy based on mathematical construction for matrix converter extending the input reactive power range," IEEE Trans. Power Electron., vol. 29, no. 2, pp. 654-664, Feb. 2014.

[2] O. Ellabban, H. Abu-Rub, and B. Ge, "A quasi-z-source direct matrix converter feeding a vector controlled induction motor drive," IEEE $J$. Emerg. Sel. Topics Power Electron., vol. 3, no. 2, pp. 339-348, Jun. 2015.

[3] E. Karaman, M. Farasat, and A. M. Trzynadlowski, "Indirect matrix converters as generator grid interfaces for wind energy systems," IEEE J. Emerg. Sel. Topics Power Electron., vol. 2, no. 4, pp. 776-783, Dec. 2014.

[4] Y. Sun, X. Li, M. Su, H. Wang, H. Dan, and W. Xiong, "Indirect matrix converter-based topology and modulation schemes for enhancing input reactive power capability," IEEE Trans. Power Electron., vol. 30, no. 9, pp. 4669-4681, Sep. 2015.

[5] Y. Sun, W. Xiong, M. Su, X. Li, H. Dan, and J. Yang, "Topology and modulation for a new multilevel diode-clamped matrix converter," IEEE Trans. Power Electron., vol. 29, no. 12, pp. 6352-6360, Dec. 2014.

[6] S. M. M. Sangdehi, S. Hamidifar, and N. C. Kar, "A novel bidirectional dc/ac stacked matrix converter design for electrified vehicle applications," IEEE Trans. Veh. Technol., vol. 63, no. 7, pp. 3038-3050, Sep. 2014.

[7] N. Y. Dai, M. C. Wong, F. Ng, and Y. D. Han, "A fpga-based generalized pulse width modulator for three-leg center-split and four-leg voltage source inverters," IEEE Trans. Power Electron., vol. 23, no. 3, pp. 14721484, May. 2008.

[8] T. Glasberger, Z. Peroutka, and J. Molnar, "Comparison of 3d-svpwm and carrier-based pwm of three-phase four-leg voltage source inverter," in Proc. 12th Eur. Conf. IEEE Power Electron. Appl. (EPE'07), Sep. 2007, pp. 1-9.

[9] X.-H. Qin, B. Zhou, H.-T. Huang, M.-M. Shi, and X.-Y. Liu, "Novel modulation strategy and decoupling algorithm for two stage three phase four leg matrix converter," in Proc. 38th Annu. Conf. IEEE Ind. Electron. Soc. (IECON'12), Oct. 2012, pp. 602-608.

[10] W. Rohouma, P. Zanchetta, P. Wheeler, and L. Empringham, "A fourleg matrix converter ground power unit with repetitive voltage control," IEEE Trans. Ind. Electron., vol. 62, no. 4, pp. 2032-2040, Apr. 2015.

[11] K. Kobravi, R. Iravani, and H. A. Kojori, "Three-leg/four-leg matrix converter generalized modulation strategy part i: A new formulation," IEEE Trans. Ind. Electron., vol. 60, no. 3, pp. 848-859, Mar. 2013.

[12] K. Kobravi, R. Iravani, and H. A. Kojori, "Three-leg/four-leg matrix converter generalized modulation strategy part ii: Implementation and verification," IEEE Trans. Ind. Electron., vol. 60, no. 3, pp. 860-872, Mar. 2013.

[13] J.-H. Kim and S.-K. Sul, "A carrier-based pwm method for threephase four-leg voltage source converters," IEEE Trans. Power Electron., vol. 19, no. 1, pp. 66-75, Jan. 2004.

[14] A. C. Ziani, A. M. Llor, and M. Fadel, "Model predictive current controller for four-leg converters under unbalanced conditions," in Proc. 14th Eur. Conf. IEEE Power Electron. Appl. (EPE'11), Aug. 2011, pp. $1-10$.

[15] W. Xiaogang, X. Yunxiang, and S. Dingxin, "Three-phase four-leg active power filter based on nonlinear optimal predictive control," in Proc. 27th Chinese Control Conf. (CCC'08), Jul. 2008, pp. 217-222.

[16] M. Rivera, I. Contreras, J. Rodriguez, R. Pena, and P. Wheeler, "A simple current control method with instantaneous reactive power minimization for four-leg indirect matrix converters," in Proc. 14th Eur. Conf. IEEE Power Electron. Appl. (EPE'11), Aug. 2011, pp. 1-9.

[17] M. Rivera, J. Rodriguez, C. Garcia, R. Pena, and J. Espinoza, "A simple predictive voltage control method with unity displacement power factor for four-leg indirect matrix converters," in Proc. 15th Int. Power Electron. Mot. Control Conf. (EPE/PEMC'12), Sep. 2012, pp. DS2c.51-DS2c.5-6.

[18] C. Garcia, M. Rivera, M. Lopez, J. Rodriguez, R. Pena, P. W. Wheeler, and J. R. Espinoza, "A simple current control strategy for a four-leg indirect matrix converter," IEEE Trans. Power Electron., vol. 30, no. 4, pp. 2275-2287, Apr. 2015.

[19] M. Preindl and S. Bolognani, "Model predictive direct speed control with finite control set of pmsm-vsi drive systems," in Proc. Pred. Control Elec. Driv. Power Electron. (PRECEDE'11), Oct. 2011, pp. 17-23.

[20] D. E. Quevedo, R. P. Aguilera, M. A. Perez, P. Cortes, and R. Lizana, "Model predictive control of an afe rectifier with dynamic references," IEEE Trans. Power Electron., vol. 27, no. 7, pp. 3128-3136, Jul. 2012.
[21] S. A. Davari, D. A. Khaburi, and R. Kennel, "An improved fcs-mpc algorithm for an induction motor with an imposed optimized weighting factor," IEEE Trans. Power Electron., vol. 27, no. 3, pp. 1540-1551, Mar. 2012.

[22] A. Formentini, A. Trentin, M. Marchesoni, P. Zanchetta, and P. Wheeler, "Speed finite control set model predictive control of a pmsm fed by matrix converter," IEEE Trans. Ind. Electron., vol. 62, no. 11, pp. 67866796, Nov. 2015.

[23] M. Zhang, D. J. Atkinson, B. Ji, M. Armstrong, and M. Ma, "A near-state three-dimensional space vector modulation for a three-phase four-leg voltage source inverter," IEEE Trans. Power Electron., vol. 29, no. 11, pp. 5715-5726, Nov. 2014.

[24] L. G. Franquelo, M. A. M. Prats, R. C. Portillo, J. I. L. Galvan, M. A. Perales, J. M. Carrasco, E. G. Diez, and J. L. M. Jimenez, "Threedimensional space-vector modulation algorithm for four-leg multilevel converters using abc coordinates," IEEE Trans. Ind. Electron., vol. 53, no. 2, pp. 458-466, Apr. 2006.

[25] M. Lopez, M. Rivera, C. Garcia, J. Rodriguez, R. Pena, J. Espinoza, and P. Wheeler, "Predictive torque control of a multi-drive system fed by a six-leg indirect matrix converter," in Proc. Int. Conf. IEEE Ind. Technol. (ICIT'13), Feb. 2013, pp. 1642-1647.

[26] M. Lopez, J. Rodriguez, C. Silva, and M. Rivera, "Predictive torque control of a multidrive system fed by a dual indirect matrix converter," IEEE Trans. Ind. Electron., vol. 62, no. 5, pp. 2731-2741, May. 2015.

[27] P. Cortes, J. Rodriguez, D. E. Quevedo, and C. Silva, "Predictive current control strategy with imposed load current spectrum," IEEE Trans. Power Electron., vol. 23, no. 2, pp. 612-618, Mar. 2008.

[28] M. Rivera, C. Rojas, J. Rodriguez, P. Wheeler, B. Wu, and J. Espinoza, "Predictive current control with input filter resonance mitigation for a direct matrix converter," IEEE Trans. Power Electron., vol. 26, no. 10, pp. 2794-2803, Oct. 2011.

[29] R. Aguilera, P. Acuna, P. Lezana, G. Konstantinou, B. Wu, S. Bernet, and V. Agelidis, "Selective harmonic elimination model predictive control for multilevel power converters," IEEE Trans. Power Electron., vol. PP, no. 99, pp. 1-1, 2016.

[30] A. K. Sahoo, K. Basu, and N. Mohan, "Systematic input filter design of matrix converter by analytical estimation of rms current ripple," IEEE Trans. Ind. Electron., vol. 62, no. 1, pp. 132-143, Jan. 2015.

[31] J. Lei, B. Zhou, X. Qin, J. Wei, and J. Bian, "Active damping control strategy of matrix converter via modifying input reference currents," IEEE Trans. Power Electron., vol. 30, no. 9, pp. 5260-5271, Sep. 2015.

[32] S. Liu, B. Ge, Y. Liu, H. Abu-Rub, R. S. Balog, and H. Sun, "Modeling, analysis, and parameters design of lc-filter-integrated quasi-z -source indirect matrix converter," IEEE Trans. Power Electron., vol. 31, no. 11 pp. 7544-7555, Nov. 2016.

[33] J. Rodriguez and P. Cortes, Predictive Control of Power Converters and Electrical Drives, 1st ed. Chichester, UK: IEEE Wiley press, Mar. 2012.

[34] P. Cortes, S. Kouro, B. L. Rocca, R. Vargas, J. Rodriguez, J. I. Leon, S. Vazquez, and L. G. Franquelo, "Guidelines for weighting factors design in model predictive control of power converters and drives," in Proc. Int. Conf. IEEE Ind. Technol. (ICIT'09), Feb. 2009, pp. 1-7.

[35] C. A. Rojas, J. Rodriguez, F. Villarroel, C. A. S. J. R. Espinoza, and M. Trincado, "Predictive torque and flux control without weighting factors," IEEE Trans. Ind. Electron., vol. 60, no. 2, pp. 681-690, Feb. 2013.

[36] J. W. Kolar, T. Friedli, F. Krismer, and S. D. Round, "The essence of three-phase ac/ac converter systems," in Proc. 13th Int. Power Electron. Mot. Control Conf. (EPE/PEMC'08), Sep. 2008, pp. 27-42. 


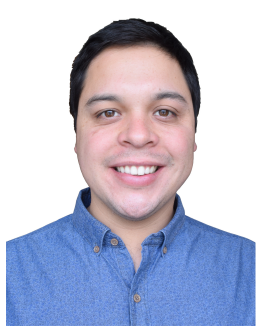

Cristian Garcia (M'16) was born in Talca, Chile, in 1987. He received the B.S. and M.S. degrees in electronics engineering from the Universidad Técnica Federico Santa María, Valparaíso, Chile, in 2013.

Mr. Garcia was awarded a scholarship from the Chilean Research Foundation CONICYT in 2013 to pursue his Ph.D. studies in power electronics at Universidad Técnica Federico Santa María, Valparaíso, Chile.

His research interests include matrix converters and model predictive control of power converters and drives.

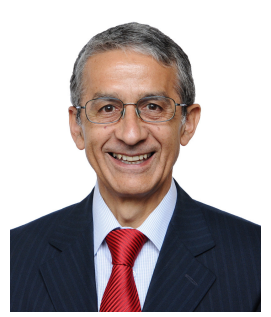

José Rodríguez (M'81-SM'94-F'10) received the engineer degree in electrical engineering from the Universidad Técnica Federico Santa María, in Valparaíso, Chile, in 1977, and the Dr.Ing. degree in electrical engineering from the University of Erlangen, Erlangen, Germany, in 1985.

In 1977, he became a Full Professor in, and the President of the Department of Electronics Engineering, Universidad Técnica Federico Santa María. Since 2015, he has been the President of the Universidad Andres Bello, Santiago, Chile. He has coauthored two books, several book chapters, and more than 400 journal and conference papers. His research interests include multilevel inverters, new converter topologies, control of power converters, and adjustablespeed drives.

Dr. Rodriguez is member of the Chilean Academy of Engineering. He is the recipient of a number of best paper awards from journals of the IEEE. He was the recipient of the National Award of Applied Sciences and Technology from the Government of Chile in 2014. He was also the recipient of the Eugene Mittelmann Award from the IEEE Industrial Electronics Society in 2015.

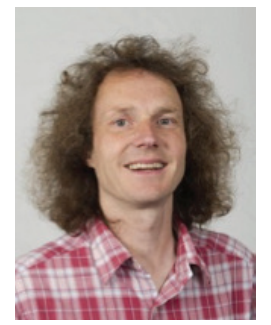

Pat Wheeler (SM'11) received the B.Eng. (with honors) degree in electrical engineering and the Ph.D. degree in electrical engineering, for his work on matrix converters, from the University of Bristol, Bristol, U.K., in 1990 and 1994, respectively.

In 1993, he moved to the University of Nottingham, Nottingham, U.K., and was a Research Assistant with the Department of Electrical and Electronic Engineering. In 1996, he became a Lecturer with the Power Electronics, Machines, and Control Group, The University of Nottingham. Since January 2008 he has been a Full Professor with the same research group. He has authored over 400 academic publications in leading international conference proceedings and journals.

Prof. Wheeler is a Member at Large and a Distinguished Lecturer of the IEEE Power Electronics Society.

Prof. Rivera was recipient of the Best PhD Thesis Award 2012, award given by the Chilean Academy of Science for PhD thesis developed in 2011 by national and foreign students in any Exact or Nature Sciences Program in Chile. In August 2015, Prof. Rivera was awarded with the Outstanding Engineer 2015 Award of the Electrical-Electronics Industry Association and the IEEE-Chile Section and also he received the Second Prize Paper Award in the 2015 IEEE Journal of Emerging and Selected Topics in Power Electronics.

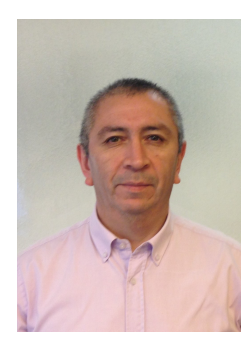

Rubén Peña (S'95-M'97) was born in Coronel, Chile. He received the B.Sc. degree in electrical engineering from the University of Concepción, Concepcion, Chile, in 1984, and the M.Sc. and Ph.D. degrees in electrical and electronics engineering from The University of Nottingham, Nottingham, U.K., in 1992 and 1996, respectively.

From 1985 to 2008, he was a Lecturer with the Universidad de Magallanes, Punta Arenas, Chile. He has been with the Department of Electrical Engineering, Universidad de Concepcion, since 2008, where he is currently a Full Professor. His research interests include control of power electronics converters, ac drives, and renewable energy systems.

Dr. Peña received the Best Paper Award from the IEEE TRANSACTIONS ON INDUSTRIAL ELECTRONICS in 2004, and the Ramon Salas Edward Award for research excellence from the Chilean Institute of Engineers in 2009 